\title{
Building information modeling for hotel buildings at the detailed design phase
}

\author{
Prof. Alaa El Din Sarhan, Mohamed EISarha \\ Anabe academy for science and technology, Abu Keer,Alex, Egypt
}

\begin{abstract}
Hotel building is developing rapidly due to the function of hotel industry. The hotel industry is transforming the traveling concept all over the world due to the development of technology and new trends. Hotel building is a facility that provide services like shelter, food, refreshment, and similar services and goods. As the buildings design and new construction trends develops; the Building Information Modeling (BIM) industry was invented. The BIM Process was developed to be managed by a BIM Execution Plan (BIMxp) that maintain the BIM process during the different phases of the project by selecting the BIM uses that provides the needed information through the different project phases. This paper aims at clarify the process of setting the importance of the BIM uses for hotel building at the detailed design phase. By analyzing the information and problems by previous researches to select the goals of the hotel building design. Then identifying the information needed and the goals that is related to the BIM uses in a matrix to determine the rank of each BIM uses.
\end{abstract}

Key words: Building information modeling, Hotel building, BIM uses, BIM execution plan, Detailed design phase.

\section{INTRODUCTION}

The hotel project is not just guest rooms, kitchen and service spaces only, it is a spaces, equipment and infrastructure. Every detail about the hotel schematic and preliminary design matters in this phase to understand the relation between the hotel spaces. [1] For better getting in deep of the project at the detailed design phase, it is a must to begin by the facility management or operation management phase to make sure that all the data and information will be imbedded in the design process and to be installed properly. [2]

This research will discuss the relation between the hotel building function, needs, challenges and the BIM uses to generate ranking of importance for each BIM uses which can be applied on hotel buildings. This ranking will facilitate for the BIM users to better prioritize the BIM uses for the hotel building BIM process. 
The research is focusing on the hotel elements and its different level of development in the detailed design phase. As there is many types and classes of the hotel buildings, the research focus on the fixed hotel building as the hotel type for this research.

The BIM process for any type of building has to be studied and developed through a BIM execution plan (BIMxp) to better maintaining the process. [2] Every project managed by a BIMxp must go through four main steps. The first step to identify the BIM uses and the team goals, the second step the design of the BIM execution process, the third step is the development of the information exchange and the fourth step is the implementation process of BIM in the project.

The research will focus on the first step only that clarify the information needed for every element in the hotel building during the detailed design phase by deciding the BIM uses required and the goals of the project. By mentioning the BIM uses and their description which matches the hotel design objectives, challenges and goals; that will generate a ranking of BIM uses in hotel buildings.

\section{BIM uses and goals}

The difference between the project goals and the BIM use is that the project goals is the desired goal for the project team or stakeholders and the BIM use is the way to achieve this goal using the different BIM tools and technology.

There is 21 BIM uses mentioned at the BIM project execution planning guide published at July 2010 that can embrace the majority of BIM uses as follows: -

1. Building (preventative) maintenance scheduling: it is the process that the functionality pf the building elements structure and equipment are well maintained over the operation life of the building. This BIM use can provide multiple value for the project as tracking maintenance history, reduce the corrective maintenance and emergency repairs, evaluate different maintenance approaches based on cost.

2. Building systems analysis: it is the process that measures the performance of the building compared to the specified design. This analysis includes the mechanical systems and all aspects that has an impact on the building performance like the solar analysis, lighting analysis, ventilation facade studies...etc. This BIM use can provide the opportunity to modify the system operations to improve the performance and ensure that the building operates as the specified design.

3. Asset management: it is a process that aid the maintenance and operation to manage the assets of a building that consisting of the physical building, systems, surrounding environment, and equipment, what must be maintained, operated or upgraded at an efficiency that satisfy the owner and user at the lowest appropriate cost.

4. Space management and tracking: it is a process that BIM will be utilized to allocate, managed and track spaces to analyze the existing use and manage client changes and future changes throughout the life cycle of the building.

5. Disaster Planning:_it is a process that the BIM model is connected with building automation system that locate the disaster, the possible routes and the harmful location within the building.

6. Record Modeling: it is the process that the BIM model records every detail information about the physical condition, environment and assets of the building. 
7. Site Utilization Planning: it is a process that use a 4D model that represent both permanent and temporary facilities on site, with the construction activity with its time frame.

8. Construction System Design (Virtual Mockup):_it is a process that 3D system design software analyzes complex building system construction.

9. Digital Fabrication: it is the process which the prefabricated object uses the machine technology to be fabricated using the 3D model.

10. 3D Control and Planning (Digital Layout): it is a process that use the model to make a layout of the building assemblies and produce lift drawings.

11. 3D Coordination: it is the process that runs with a clash detection software to determine filed conflicts by comparing 3D models of building systems.

12. Design Authoring: it is the process BIM tools develop models and analyses it to suite the design criteria by audit and analysis tools connected to the 3D BIM model.

13. Engineering Analysis (Structural, Lighting, Energy, Mechanical, Other): it is the process that intelligent modeling software uses the BIM model to determine the most effective engineering method based on design specifications.

14. Sustainability (LEED) Evaluation: it is the process that uses the BIM model to be evaluated in their life cycle to achieve the sustainability through the project's stages.

15. Code Validation: it is the process that BIM models is checked with code validation software to achieve a specific code.

16. Design Review: it is the process that the $3 \mathrm{D}$ model is used to evaluate the program and the set criteria to showcase the design to the stakeholder by using a virtual mock-up to reduce the cost and time spent in real mock-ups.

17. Programming: it is the process that a spatial program is used to assess efficiently and accurately the design performance for the requirement needed for the project. this process add value to the project by discussing the critical decisions and best approach.

18. Site Analysis: it is the process that evaluate properties using BIM and GIS tools for a given area to choose the most efficient site location for the future project.

19. Phase Planning (4D Modeling): it is the process that effectively plan the phased occupancy in retrofit, addition, renovation, or showing the construction sequence and required spaces for the building site.

20. Cost Estimation: it is the process that the BIM model generate an accurate quantity takeoff and cost estimation early in the design phase to prevent over budget.

21. Existing Condition Modeling: it is the process that a BIM model is generated to describe the existing condition for the site.

After describing the BIM uses the hotel buildings objectives, challenges and goals must be clarified and listed to assign every BIM use to a challenge or goal or objective.

Hotel building objectives and goals.

The hotel building is a commercial project that needs to be profitable. Firstly, the hotel building is a vision, a concept that have to came to reality. Then it requires a design brief that includes the location with opportunities and the budget available or required for the project. After the design brief is set the design team moves to the costing phase that study the feasibility and the revenue of the project. At this stage the detailed design has to be set to make the coordination required then get the tendering and the implementation. (Figure 4.1) 


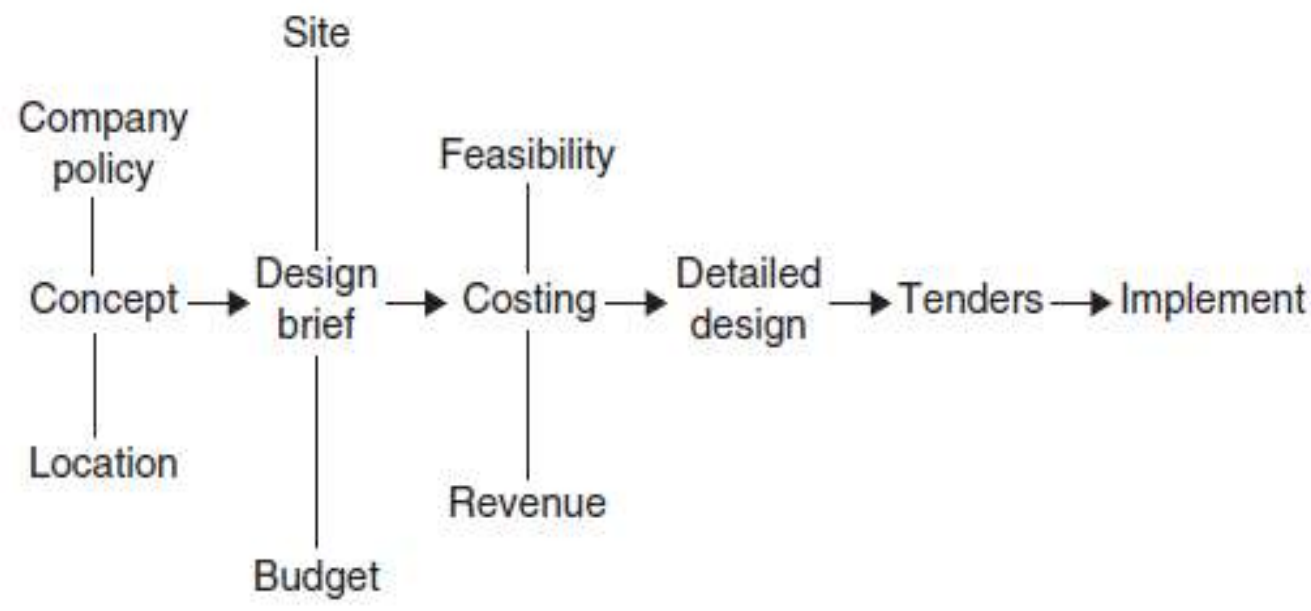

Fig Error! No text of specified style in document.1: a model of the hospitality design process (Source: Developing Hospitality Properties and Facilities, second edition 2004)

There are design factors that can impact on the hotel or building as the main task for the designer is to make a harmonious balance between four factors. The first factor is the image of the facility, the second factor the style of the hotel, these two factors are like the identity, the brand and the quality.

The third factor is the operating efficiency and the forth factor is the customer comfort. These two factors are how the facility is operated properly from the operator perspective and the guest perspective. [3]

When making the harmonious balance between the four factors there is main elements of design the designer must be considered as followed: -

- Space planning

- Form and color

- Finishes and durability

- Lighting and audio-visual systems

- Technology

- Costs

Considering these elements, the designer acts as the interface between the building form, structure, building services and the operation to bring the project to reality.

The main challenges that relates to the AEC industry that face the hotel and hospitality industry in the twentieth century and is the main reason of the latency and over budget projects are as follows [3]: -

- Differentiate its full-service brands between each other and those of the competition.

- Standardize product and still reflect local culture and environment.

- Establish a management structure for a worldwide multiproduct, service and operating group.

- Maintain or extend planned product life cycles.

- Deal with rising market fragmentation in terms of age, culture and consumer lifestyle aspirations.

Other external factors that will continue to impact on the industry's development:

- Environmental considerations and consumer expectations.

- Increased consumer protection legislation and liability claims. 
- Increased recognition of minority group requirements and legislation aimed at reducing discrimination against, for example, disabled persons.

These challenges can lead to changes during the Planning process



\begin{tabular}{|l|l|l|l|l|}
\hline Feasibility & Pre-design & Design & Pre-construction & Construction \\
\hline & & & & \\
\hline
\end{tabular}

Fig 2 : Change Cost diagram (Source:Developing Hospitality Properties and Facilities, Second Edition 2004)

The diagram is very close of the Macleamy diagram of effort to cost between traditional process and BIM process. (Figure 2)

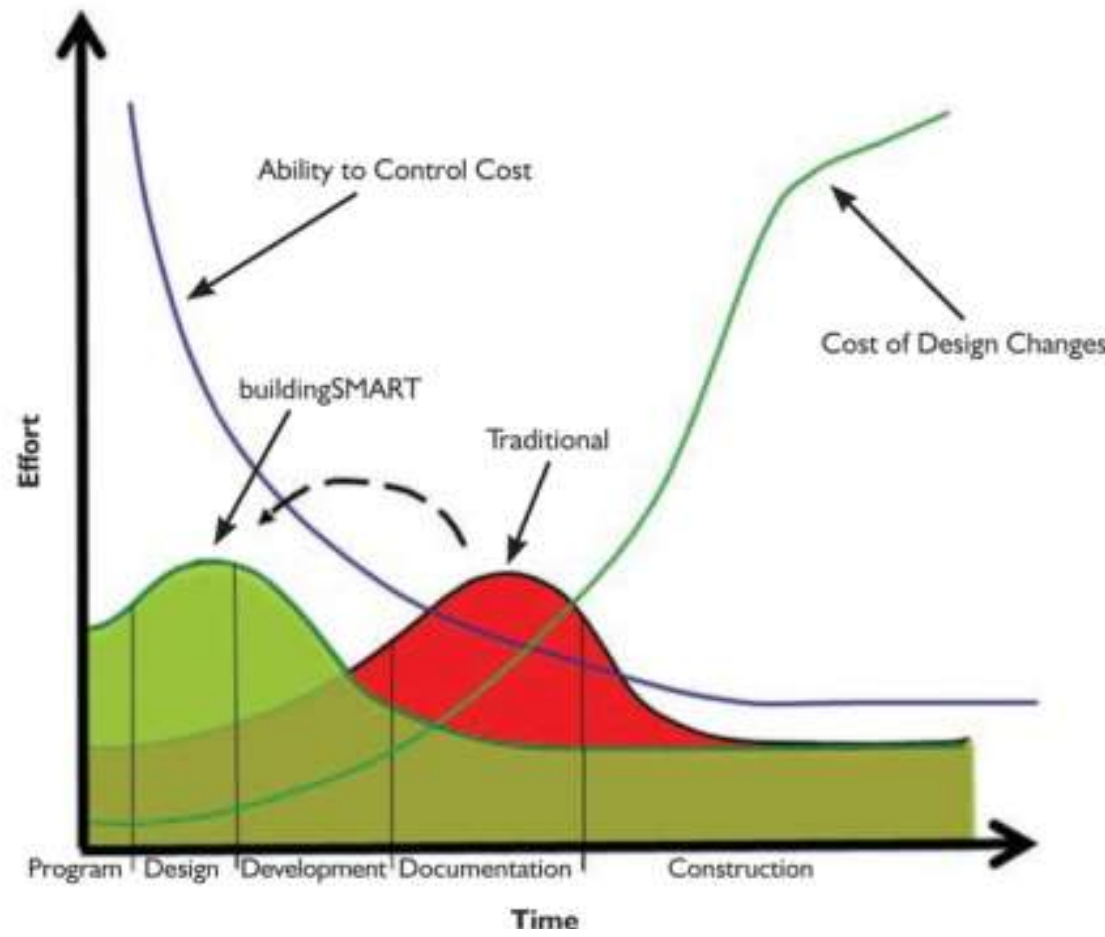

Fig 3 : Effort versus cost curve. (Source: HOK CEO Patrick MacLeamy)

These diagram reveals that the BIM is suitable for the Hotel planning process that shifts the changes and effort for the project to the design phase. The challenges and design elements can be related to buildings elements and BIM uses. 
There are more factors that must be involved in the choice of BIM use for Hotel buildings at the construction phase as it mentioned at the creative construction company held in Cairo, Egypt at 2014. [4]

There are five main categories that delays the completion and overdue the planned budget. (Table 1)

Table 1 : Factors causing increase in time and/or cost of hotel building in Egypt (Source: Creative construction conference, 2014)

\begin{tabular}{|l|l|} 
Wesign Mistakes (contradictions between design and existing conditions) \\
Wrong estimation of quantities as well as wrong / incomplete specifications \\
Underestimation of renovation required logical duration for completion \\
Under-estimation of testing and commissioning duration as well as soft \\
opining and grand opining durations \\
Under-estimation of the required labor resources for the renovation \\
Wrong choice of contractual procurement methodology
\end{tabular}




Guest complaints leading to holding the renovation for a period of time or
to increasing the buffer zones
Difficulties of getting the required permits, especially occupation and
operation permits and Civil Defense Authority Requirements
Unavailability of some materials in the local markets
Non-availability of skilled labor for similar kinds of finishing works
Political Unrest (before 2011)

As mentioned in other research focus on Chinese hotels the main causes is: [5]

1) the Procurements process delays.

2) the non-compliance with the brand standard issues.

3) the delay in activities and poor execution.

4) delay in licenses and permits.

5) delays in fire life safety process.

6) delays in concept, design, construction and handover.

As mentioning the factors and elements at the concept to the design phase to the construction phase through the detailed design phase, the operation phase must be noted.

As HOK Chief Executive Officer Patrick MacLeamy explains the BIM, BAM, BOOM concept at the BIMForum Keynote with a title of the promise of BIM at Boston in April 2014. He explains the future of BIM as BIM is for Building information modeling and it can be used in the design and create alternative solutions to reach the optimum design. As BAM is for Building Assembly modeling as nowadays the buildings are assembled with the many prefabricated products or components. The BOOM is for Building Operation Optimization Modeling that is the most important phase in the life cycle of a building.

He mentioned that every 1USD spent at the design phase relates of a 20USD at the construction phase and a 60USD which made the operation phase the most important phase in the life cycle of the building and cannot be ignored in this research.

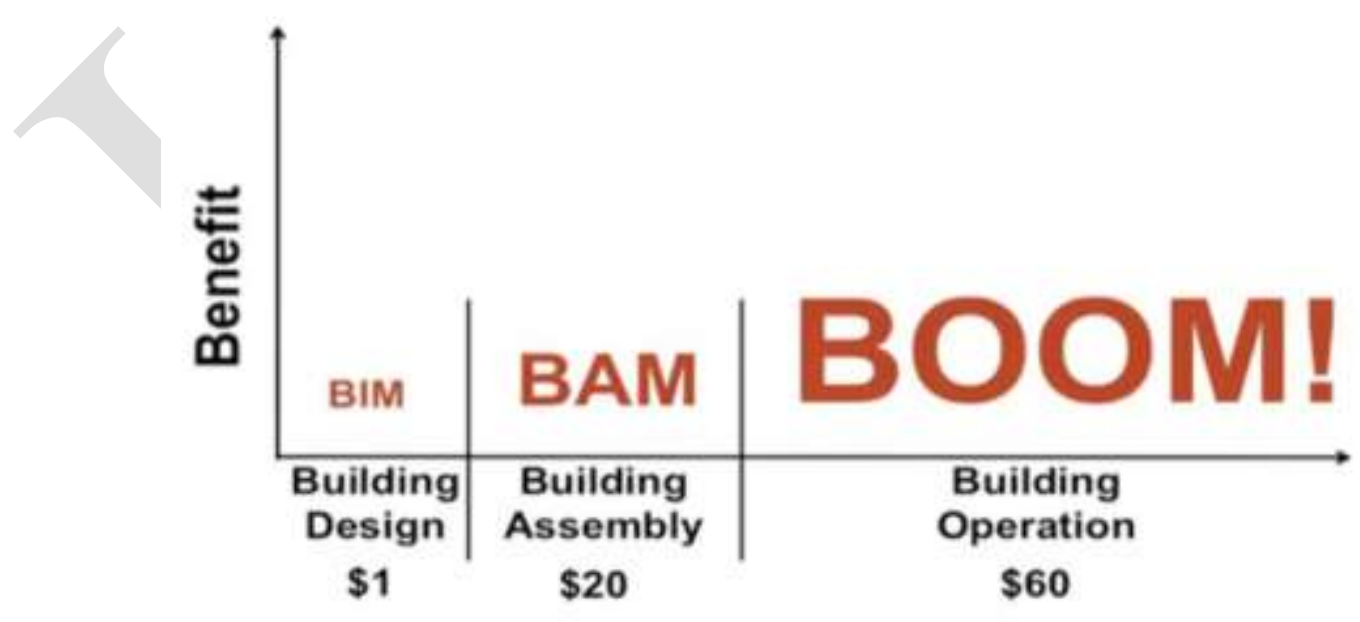

Time

Fig 4: BIM BAM BOOM Chart (Source:https://www.archdaily.com/262008/the-future-ofthe-building-industry-bim-bam-boom) 
By mentioning the operation phase, the maintenance management has the most related activity to AEC. There is three common approach for maintenance management, first there is the failure driven maintenance which contain the corrective maintenance and the emergency maintenance. Second approach is the time-based maintenance which contain the minor, major periodic maintenance and the routine preventive maintenance. the third approach conditionbased maintenance which contains predictive maintenance and periodic condition monitoring of critical equipment. [6]

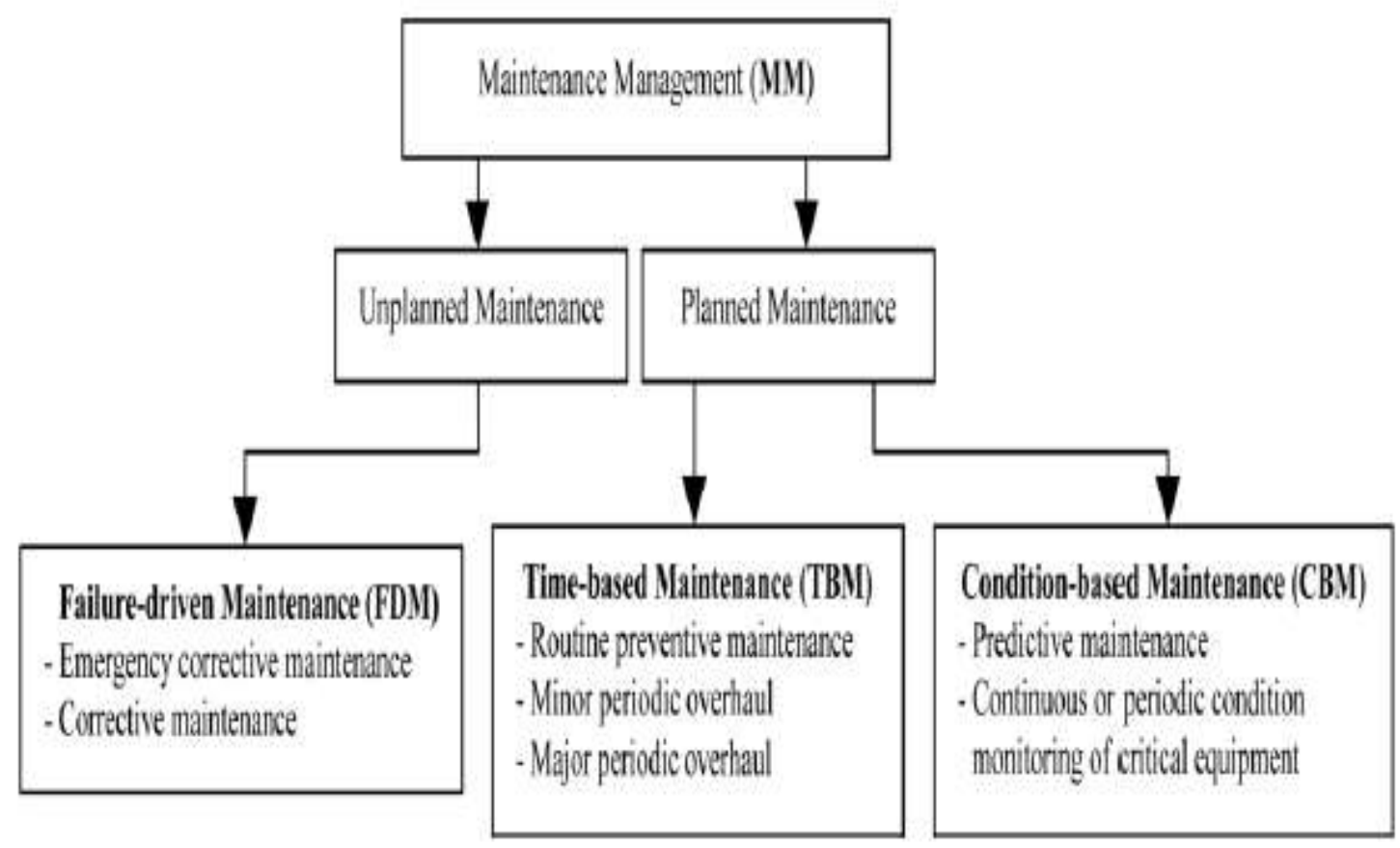

Fig 5: Maintenance Management Approaches (Source: (Aryee, 2011))

The MIT building systems design handbook version 1.2 mentioned the maintenance process and the coordination required check points that have to be checked with other phases and parties.

First, the coordinate construction operation to assure the efficient and orderly installation, connection and operation as: -

- schedule construction operations for the sequence required for installation of the parts.

- Coordinate installation of different components to make sure the best accessibility required for maintenance, service and repair.

- Make assumption for extra items can be placed later.

Second, create written messages for involved parties outlining the main procedure required for coordination.

Third, make a coordinate scheduling and timing for administration procedures with the construction activities to avoid conflicts and order as follows, but not limited:

- Preparation schedules.

- Installation and removal of temporary facilities.

- Delivery and process of submittals.

- Progress meetings.

- Project closeout activities. 
Fourth, the conservation of energy, water and material to make sure that is carried out.

Every Hotel building must have a list of operation and maintenance activities as follow:

- A fixed maintainance schedule for inspecting and correcting rooms and spaces failure.

- Documentation ina binder or an electronic copy with a master cover sheet listing for rooms and spaces noting the preventative maintenance.

- Establish and maintain an operation and maintenance manual library for all equipment and systems at the hotel.

- Maintain building plans and keep the set secured. This set must be updated and reflect the current system.

- Asset list of equipment and system for MEP.

- Maintain log books and log daily sheets with records for primary systems and equipment.

- Maitain a preventive maintenance program.

- Energy and water conservation program.

- A water treatment program.

By choosing the related factors and elements required at the detailed design phase in hotel buildings and its relation in a table. This table shows each goal at the first column and the required BIM uses at the first row. To obtain an understanding of the ranking of BIM uses and goal description a scoring for 1 will be applied to each BIM use relates to a goal and a zero scoring for if else as shown in Table 2.

By making a scoring sum for every BIM use it will reflect the ranking as follows: -

1. Design Authoring

2. Site Analysis

3. Phase Planning (4D Modeling)

4. 3D Coordination

5. Space Management and Tracking

6. Engineering Analysis (Structural, Lighting Energy, Mechanical, Other)

7. Site Utilization Planning | Design Review

8. Building System Analysis

9. Programming | Construction System Design (Virtual Mockup)

10. Cost Estimation

11. Building Preventative Maintenance Schedule

12. Code Validation | Record Modeling

13. Asset Management

14. Existing condition Modeling

15. Digital Fabrication

16. Sustainability (LEED) Evaluation |3D Control and Planning (Digital Layout)

17. Disaster Planning 
Table 2 Hotel Building goals and BIM uses (Source: Author)

\begin{tabular}{|c|c|c|c|c|c|c|c|c|c|c|c|c|c|c|c|c|c|c|c|c|c|c|}
\hline 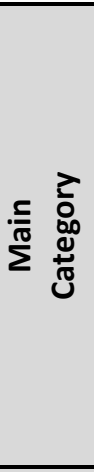 & Goal/BIM Uses & 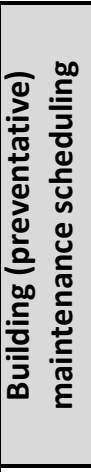 & 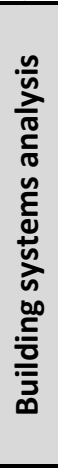 & 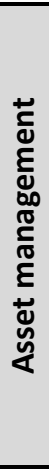 & 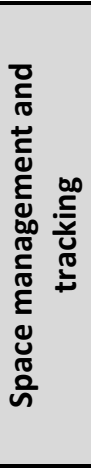 & 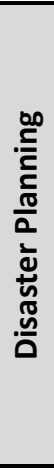 &  & 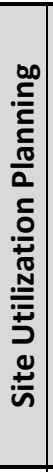 & 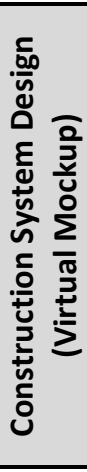 & 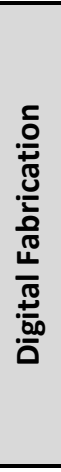 & 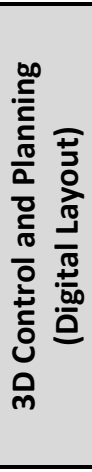 & 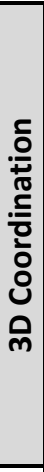 &  & 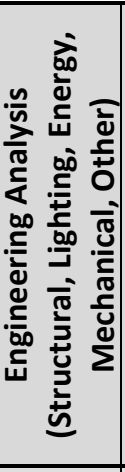 & 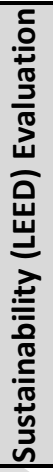 & $\begin{array}{l}\frac{2}{0} \\
\frac{2}{\pi} \\
\frac{\pi}{\pi} \\
\frac{\pi}{\pi} \\
\frac{0}{0} \\
0\end{array}$ & 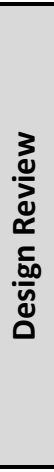 &  & $\begin{array}{l}\frac{n}{n} \\
\frac{n}{n} \\
\frac{c}{4} \\
\frac{0}{n} \\
\frac{\pi}{n}\end{array}$ &  & 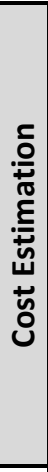 & 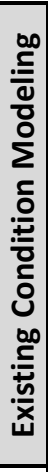 \\
\hline \multirow{16}{*}{ 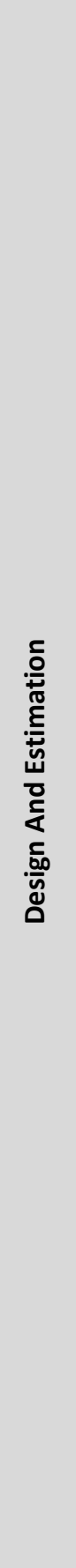 } & Space planning & & & & & & 1 & & & & & & 1 & & & & & & & & & \\
\hline & Form and color & & & & & & 1 & & & & & & 1 & & & & & & & & & \\
\hline & $\begin{array}{cc}\begin{array}{c}\text { Finishes } \\
\text { durability }\end{array} & \text { and } \\
\end{array}$ & & & & & & 1 & & & & & & 1 & & & & & & & & & \\
\hline & $\begin{array}{l}\text { Lighting and audio- } \\
\text { visual systems }\end{array}$ & & & & & & 1 & & & & & & 1 & & & & & & & & & \\
\hline & Technology & & & & & & 1 & & & & & & 1 & & &  & & & & & & \\
\hline & Costs & & & & & & 1 & & & & & & 1 & & & & & & & & & \\
\hline & $\begin{array}{l}\text { Differentiate its full- } \\
\text { service brands } \\
\text { between each other } \\
\text { and those of the } \\
\text { competition. }\end{array}$ & & & & 1 & & & & & & & 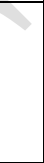 & & & & 1 & 1 & 1 & & & & \\
\hline & $\begin{array}{lr}\text { Standardize } & \text { product } \\
\text { and still reflect } & \text { local } \\
\text { culture } & \text { and } \\
\text { environment. } & \\
\end{array}$ & & & & 1 & & & & & & & & & & 1 & 1 & 1 & 1 & & & & \\
\hline & $\begin{array}{l}\text { Establish a } \\
\text { management structure } \\
\text { for a worldwide } \\
\text { multiproduct, service } \\
\text { and operating group. }\end{array}$ & 1 & & 1 & 1 & & & & & & & & 1 & 1 & & 1 & 1 & 1 & & & & \\
\hline & $\begin{array}{l}\text { Maintain or extend } \\
\text { planned product life } \\
\text { cycles. }\end{array}$ & 1 & 1 & 1 & 1 & & & & & & & 1 & & 1 & & & & & & & 1 & 1 \\
\hline & $\begin{array}{l}\text { Deal with rising } \\
\text { market fragmentation } \\
\text { in terms of age, culture } \\
\text { and consumer lifestyle } \\
\text { aspirations. }\end{array}$ & & & & & & & & & & & & & & & & 1 & 1 & & & & \\
\hline & $\begin{array}{l}\text { Environmental } \\
\text { considerations and } \\
\text { consumer } \\
\text { expectations. }\end{array}$ & & & & 7 & & & & & & & & & & 1 & & 1 & 1 & 1 & & & \\
\hline & $\begin{array}{l}\text { Increased consumer } \\
\text { protection legislation } \\
\text { and liability claims. }\end{array}$ & 1 & 1 & & 1 & 1 & & & & & 1 & 1 & 1 & 1 & & & 1 & & & & & \\
\hline & $\begin{array}{l}\text { Assure the fire life } \\
\text { safety process. }\end{array}$ & 1 & 1 & & & 1 & & & & & & & & 1 & & 1 & 1 & 1 & 1 & & & \\
\hline & $\begin{array}{l}\text { Increased recognition } \\
\text { of minority group } \\
\text { requirements and } \\
\text { legislation aimed at } \\
\text { reducing } \\
\text { discrimination against, } \\
\text { for example, disabled } \\
\text { persons. }\end{array}$ & & & & 1 & & & & & & & & & & & 1 & 1 & 1 & 1 & & & \\
\hline & $\begin{array}{l}\text { Preventing design } \\
\text { mistakes } \\
\text { (contradictions } \\
\text { between design and } \\
\text { existing conditions) }\end{array}$ & & 1 & & & & & & 1 & 1 & 1 & 1 & 1 & 1 & & 1 & 1 & 1 & & 1 & & 1 \\
\hline
\end{tabular}


DOI : https://dx.doi.org/10.26808/rs.ed.i8v5.01

International Journal of Emerging Trends in Engineering and Development

Issue 8, Vol.5 (Aug-Sep 2018)

Available online on http://www.rspublication.com/ijeted/ijeted_index.htm

ISSN 2249-6149






\begin{tabular}{|c|c|c|c|c|c|c|c|c|c|c|c|c|c|c|c|c|c|c|c|c|c|c|}
\hline 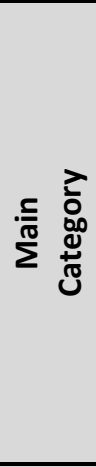 & Goal/BIM Uses & 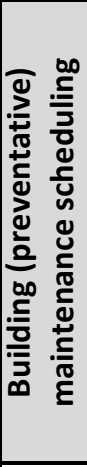 & 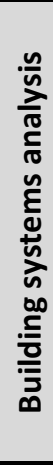 & 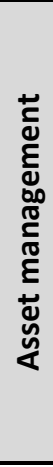 & 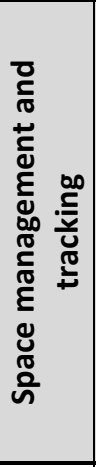 & 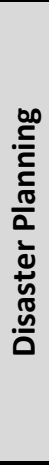 & 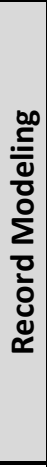 & 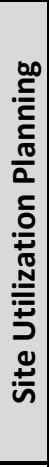 & 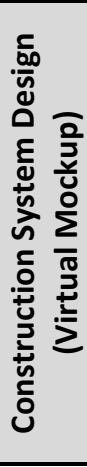 & 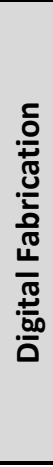 & 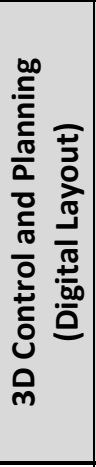 &  &  & 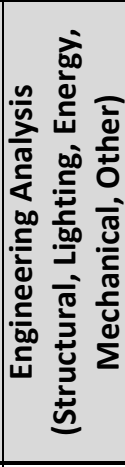 & 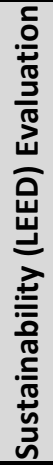 & $\begin{array}{l}\frac{}{0} \\
\frac{0}{7} \\
\frac{0}{0} \\
\frac{.0}{\pi} \\
\frac{0}{0} \\
\frac{0}{0} \\
0\end{array}$ & 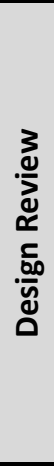 & 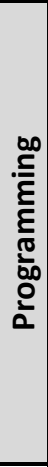 & $\begin{array}{l}\frac{n}{n} \\
\frac{n}{0} \\
\frac{c}{4} \\
\frac{0}{n}\end{array}$ & 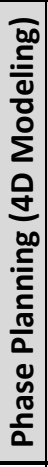 & 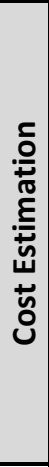 & 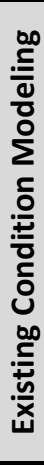 \\
\hline \multirow{6}{*}{$\begin{array}{l}\frac{5}{0} \\
\frac{0}{0} \\
\frac{0}{0} \\
\frac{1}{0} \\
0\end{array}$} & $\begin{array}{l}\text { Taking decisions and } \\
\text { permissions } \\
\text { operator on time }\end{array}$ & 1 & 1 & & 1 & & & 1 & & & & 1 & 1 & 1 & & & & & 1 & 1 & & \\
\hline & $\begin{array}{l}\text { Taking decisions by } \\
\text { owner on time }\end{array}$ & 1 & 1 & & 1 & & & 1 & & & & 1 & 1 & 1 & & & & & 1 & 1 & & \\
\hline & $\begin{array}{l}\text { Taking decisions by } \\
\text { consultant on time }\end{array}$ & 1 & 1 & & 1 & & & 1 & & & & 1 & 1 & 1 & & & & & 1 & 1 & & \\
\hline & $\begin{array}{l}\text { Effective coordination } \\
\text { between procurement } \\
\text { team and contractor }\end{array}$ & & & & & & & 1 & 1 & & & 1 & 1 & & & & & & 1 & 1 & 1 & \\
\hline & $\begin{array}{l}\text { Large number of } \\
\text { different discipline } \\
\text { contractors and } \\
\text { effective coordination } \\
\text { between them }\end{array}$ & & & & 1 & & & 1 & 1 & & & 1 & 1 & & & & & & 1 & 1 & & \\
\hline & $\begin{array}{l}\text { Effective coordination } \\
\text { with interior designer } \\
\text { to take decision } \\
\text { making on time }\end{array}$ & 1 & 1 & & 1 & & & 1 & 1 & & & 1 & 1 & 1 & 1 & & & & 1 & 1 & & \\
\hline \multirow{3}{*}{ 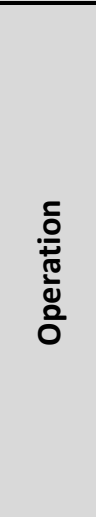 } & $\begin{array}{l}\text { Schedule construction } \\
\text { operations for the } \\
\text { sequence required for } \\
\text { installation of the } \\
\text { parts. }\end{array}$ & 1 & 1 & 1 & 1 & & 1 & & & & 1 & & & & & & & & & & & \\
\hline & $\begin{array}{l}\text { Coordinate installation } \\
\text { of different } \\
\text { components to make } \\
\text { sure the best } \\
\text { accessibility required } \\
\text { for maintenance, } \\
\text { service and repair. }\end{array}$ & & 1 & 1 & 1 & & & & 1 & & & 1 & 1 & 1 & & & 1 & & 1 & 1 & & \\
\hline & $\begin{array}{l}\text { Make assumption for } \\
\text { extra items can be } \\
\text { placed later. }\end{array}$ & 1 & 1 & 1 & 1 & & 1 & 1 & 1 & & & 1 & 1 & 1 & & & 1 & & 1 & 1 & 1 & \\
\hline $\begin{array}{l}\text { Total } \\
\text { BIM } \\
\text { uses }\end{array}$ & & 10 & 13 & 8 & 17 & 2 & 9 & $\begin{array}{l}1 \\
4\end{array}$ & 12 & 4 & 3 & $\begin{array}{l}1 \\
8\end{array}$ & $\begin{array}{l}2 \\
2\end{array}$ & 15 & 3 & 9 & 14 & $\begin{array}{l}1 \\
2\end{array}$ & $\begin{array}{l}2 \\
0\end{array}$ & $\begin{array}{l}1 \\
9\end{array}$ & $\begin{array}{l}1 \\
1\end{array}$ & 6 \\
\hline
\end{tabular}

\section{CONCLUSION}

The hotel buildings are a special type of building that required a special BIM planning to achieve the best performance, reduce money and time completing the project. The most common BIM use for hotel Goals which is strongly required to obtain the BIM process is to create a model using authoring tools so design authoring BIM use comes at the first place. Neglecting the site analysis as a schematic design phase as it is not a detailed design phase BIM use. At the second place comes the planning or the 4D modeling as the hotel building is considered as a commercial and at the variety of cases it is gaining their profit seasonal [3]. The 3D coordination come at the third place to facilitate and reduce the time and money for the project to prevent the rework and clash detection. Neglecting the space management and 
tracking as it is a BIM use that relates to the operation Phase. At the fourth place comes the engineering analysis and then the design review. At the fifth place comes the cost estimation or the cost management as the BIM uses programming, design review, code validation, site utilization planning and construction system design are not applicable in the detailed design phase.

\section{REFERENCES}

I. J. A. deRoos, "Planning and Programming a Hotel," Hospitality Administration and Management Commons, 2011.

II. C. I. C. R. P. CIC, BIM Project Execution Planning Guide - Version 2.0, The Pennsylvania State: The Pennsylvania State University, 2010.

III. Josef Ransley, Hadyn Ingram, Developing Hospitality Properties and Facilities, Burlington: Elsevier Butterworth-Heinemann, 2004.

IV. Mohamed Abdelghany,PhD. , Ibrahim Abotaleb, "Causes of hotel renovation delays in Egypt," in Creative Construction Conference , Cairo, 2014.

V. Gret Noodry, Richard Whitfield, 29 May 2018. [Online]. Available: https://www.apm.org.uk/sites/default/files/root\%20causes\%20of\%20new\%20hotel\%20op ening\%20delays\%20in\%20greater\%20china\%20(2014-12-01).pdf.

VI. S. Aryee, "HOTEL MAINTENANCE MANAGEMENT Strategic practices in hotel operation," Stockholm, 2011. 